\title{
Dual Epidermal Growth Factor Inhibition and Multi Targeted Epigenetic Therapy (MTET)
}

\author{
Mohammad Nezami*, Steve Hager \\ Pacific Medical Center of Hope and Research Cancer Institute of America, Fresno, CA, USA \\ Email: ^amnezami@yahoo.com
}

How to cite this paper: Nezami, M. and Hager, S. (2018) Dual Epidermal Growth Factor Inhibition and Multi Targeted Epigenetic Therapy (MTET). Journal of Cancer Therapy, 9, 872-882.

https://doi.org/10.4236/jct.2018.911072

Received: October 25, 2018

Accepted: November 11, 2018

Published: November 14, 2018

Copyright (๑) 2018 by authors and Scientific Research Publishing Inc. This work is licensed under the Creative Commons Attribution International License (CC BY 4.0).

http://creativecommons.org/licenses/by/4.0/

\begin{abstract}
Since the discovery of tyrosine kinase inhibitors in treatment of lung cancer harboring such actionable targets, many lives have been prolonged. To the same extent, same group of patients have failed to benefit from this category of drugs, in long run, either initially or during the course of treatments, simply due to either known or unknown mechanism of resistance which occurs very often in the first few months after initiation of therapy. The resistance is 100 percent expected, and no patient is reported to be a waiver of such pattern. With best practices of oncology, the average duration of response is expected to be below 12 months [1]. About half of the resistance is caused by mutation at T790M in EGFR target, which can be revealed by liquid biopsy [1] [2]. The most recent studies have revealed the significant role of epigenome in controlling this complicated resistance pattern. We have learned that Histone deacetylation, as opposed to promoter methylation, may contribute to the epigenetic silencing and to EGFR TKI resistance in NSCLC [3] [4]. Here we present a case study with a model of combinational therapy that targets the EGFR molecule, (by small molecule inhibitor, Afatanib) with simultaneous epigenetic modification of the target, (by application of multitargeted epigenetic therapy (MTET) with significantly improved clinical results. We propose further trials are needed to support such hypothesis, which if proved, could significantly shift the current practices in management of this set of cases in lung adenocarcinomas.
\end{abstract}

\section{Keywords}

Epidermal Growth Factor, Lung Cancer, Epigenetic Therapies, Targeted Therapies, Afatinib

\section{Background}

Several categories of resistance have been speculated to be responsible for mole- 
cular resistance in EGFR mutated and treated cases with EGFR inhibitors. Most common one is the Gatekeeper mutation in EGFR: T790M mutation. Although most common, this has better post progression/survival prognosis (PPS) compared to other groups of patients with other mechanisms of resistance. Approximately $50 \%$ of the acquired resistance developed to erlotinib or gefitinib is linked to T790M mutation and the proportion could be underestimated as more accurate prevalence of $68 \%$ was achieved using LNA-PCR/sequencing assay [5]. Second is Compensatory contribution of other RTKs: MET receptor, a transmembrane tyrosine kinase encoded by proto-oncogene MET, has been highlighted as an important cause for acquired resistance of NSCLC to gefitinib or erlotinib. Due to connection of Hepatocyte growth factors to Met pathway, it is speculated that in about 61 percent of cases, studies in Japan, HGF overexpression was responsible in promoting drug resistance [6]. This mechanism is INDEPENDENT of TKI pathways. Third mechanism of resistance is Activation of compensatory signaling pathways, mostly reported Pi3k/Akt/M-tor pathway. AKT activation and mTOR phosphorylation were frequently present in NSCLC patients $(43 \%-90 \%$ and $60 \%-90 \%$, respectively. That said application of several dual targeted therapies to target $\mathrm{Pi} 3 \mathrm{k} / \mathrm{Akt}$, has not resulted in improved survival in these patients [7]. Her 2 alteration, is seen in about 2 percent of cases. Finally Epidermo mesenchymal Transition (EMT) phenotypic transformation has been proven in at least 5 percent of cases with EGFR resistance as main mechanism. [8] [9] [10].

Since Met/PI3K and EMT transition are all targets for epigenetic modification it appears reasonable for addition of histone deacetylase inhibitors in combination of DNA demethylating agents, ina package under multitargeted Epigenetic Therapy protocol (MTET) to the patients to both prevent and treat the molecular resistance.

What to our knowledge was never reported was addition of epigenetic therapies in clinic to patients with EGFR mutation carcinomas, specifically in case of T790 M mutation. Here we study a case series of 2 patients with such phenomenon and report a significant effect size in their response when epigenetic therapies are implemented under the multitargeted Epigenetic Therapy protocol (MTET).

\section{Methods and Materials}

2 cases with advanced stage four lung adenocarcinoma were identified by screening a pool of 25 patients with lung cancer. These patients were both Asian American, one female and one male, ages 54 and 55 year old, treated with combination of a his tone deacetylase inhibitor (PB) and a polyphenol known for DNA demethylating effect. The therapy was provided through intravenous administration. The patients were counselled about their care and consented appropriately. Early molecular response was defined by measurable change in the MAF after first cycle of therapy in two weeks. Major molecular response was de- 
fined by $2.5 \log$ decrease in mutated allele fraction (MAF) of altered genes. The response met the criteria for early and major molecular response (EMR/MMR).

\section{Case studies}

Case 1:

54 years old female with history of EGFR mutated lung adenocarcinoma, metastatic to brain, status post gamma knife on 10/16, and left cerebellar resection on 10/16 and left VATS procedure on 4/2017, Glilotrif started in 2016, with good response for about 3 months, further progression of her disease in her skeletal bones and lungs, has a propose negative T790 M mutation in her Travogene test, referred to us in February 2018, for evaluation and treatments.

At the time of her initial evaluation, she had pain in her back, as a result of her tumor in her spine (T4), she also had noticed an enlarged left axillary node, for about 2 months, Her CEA had increased from 11 to 26, in 6 months.

Our initial labs confirmed the presence of EGFR mutation at T790 M, as well as increased CYFRA 21.1 and IGF-1. Immediately she was started on IV epigenetic therapies per MTET protocol, which she received on daily basis for two weeks. Her labs further were repeated on March $9^{\text {th }}$, which showed reduction of her circulating DNA MAF (mutation allele fraction) from 31 percent down to 5 percent in her EGFR. (plus APC, Kit, BRAF, MET alteration reduced or disappeared). Her blood test also confirmed reduction of her ALK-P, CRP and LDH. (normalized) Her IGF-1 also normalized at 118 (on 3/9/18). See Figure 1.

\section{Case 2:}

55 years old male with history of right upper lobe mass in the lung about 4.5 $\mathrm{cm}$ in size diagnosed as adenocarcinoma, EGFR positive(he had been diagnosed after a LN biopsy, which was positive after a period of time when he was only suspected to have unknown primary adenocarcinoma in October 2017). He unfortunately had wide spread bone(sternum, spine, femur, pelvic) and brain lesions(frontoparietal lobe and cerebellum), was unable to walk, due to wide metastatic disease in brain and cerebellum, further he was treated with cyberknife and Afatanib, since December 2017, as his tumor was EGFR positive. He has been referred to us by his PMD for evaluation and treatments.

His bone scan had shown several areas of metastatic disease, including bilateral ribs, sacrum, cervical, thoracolumbar spine, left humerus, femur, ilia bone, and sternum, on 10/29/17. His CT of chest showed innumerous pulmonary nodules, as well as a large mass in right upper lobe, in the size of $4.5 \mathrm{~cm} \times 2.5 \mathrm{~cm}$, as well as lesions in left lung apex and pleural based nodules, multiple mediastinal and hilar LNs. His MRI of brain had shown, multiple lesions, largest in right frontoparietal lobe with $2.3 \times 2.3 \mathrm{~cm}$ size, along with second largest in midline, $1.5 \mathrm{~cm}$ in size, many smaller lesions, with accompanying hemorrhagic features and vasogenic edema. CT of abdomen, multiple liver lesions identified.

Upon his arrival, his labs were drawn and it showed increased CEA at 14.4. His liquid biopsy was positive for RB1, and EGFR, collected on 12/11/17. (Please see Figure 2). 


\section{1 (A9282901)}

DOB: MAY-31-1063 | Test Number 2

\section{GUARDANT360}

$\begin{array}{ll}\text { Patient } & \text { Reporting } \\ \text { MRN } & \text { REPORT DATF } \\ - & \text { MAR-17-2018 } \\ \text { GENDER } & \text { RECEIPT DATE } \\ \text { Female } & \text { MAR-10-2018 } \\ \text { CLINICAL DIAGNOSIS } & \text { COUECTON DATE } \\ \text { Lung adenocarcinoma } & \text { MAR-09-2018 } \\ & \text { SPECIMEN } \\ & \text { BloOd }\end{array}$

Physician

NAME

Mohammad Amin Nezami

ACCOUNT

Pacific Medical Center of Hope

1680 E Herndon Ave Ste 102, Fresno, CA 93720

PHONE FAK

(559) $439-5393$

ADDITIONAL. RECIPIENT

Guardant360 Tumor Response Map

The Gilardant360 Tumor Response Map illustrates the mutant allele porcontago (\% cfDNA) of observed somatic variarts at each sample submission tirrle point. The "Somatlc Alteration Burden" value veluw refers to the maximum \% cfDNA detected at each time point. Amplifications are not plotted, and only the first and last four test dates are plotted. Please see the Physician Portal (ht1ps://portal.guardanthealth.com) for the Tumor Response Map with all tost datos.

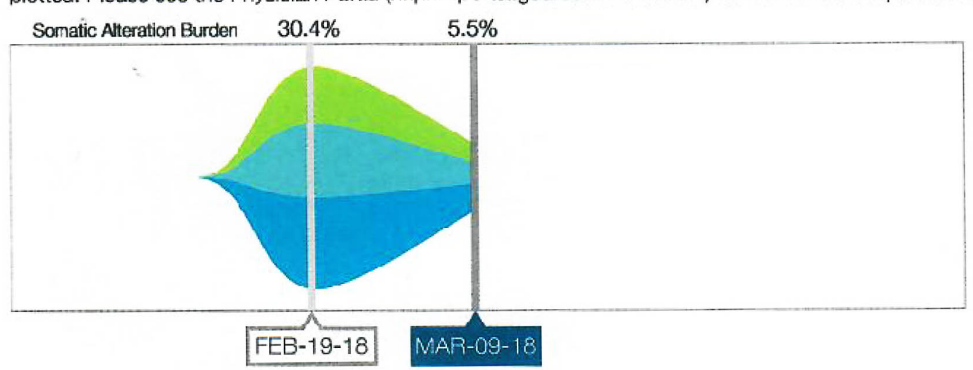

\section{Total Somatic Alteration(s) Detected}

4 with Associated Therapy

1 Associated with Lack of Response

Multiple Clinical Trials Available

Summary of Somatic Alterations \& Associated Treatment Options

I he percentage of altered cell-free DNA (\% cfDNA) circulating in blood is related to the unique tumor biology of each patient. Factors that may affect the \% cfDNA of detected somatic alterations include tumor growth, turn-over, size, heterogeneity, vascularization, disease progression, and treatment.

Alteralion

Mutation Irend
Amplification
FDA Approved in

Indication

see page 3
Available for Use in

Other Indication

soe page 3
Cliniral Drug Trials

soc page 9

GUARDANT HEALTH For a more detailed Guardant360 Patient Report, log onto: https://portal.guardanthealth.com or to set up anl accuunt, contact Client Services: 855.698.8887 


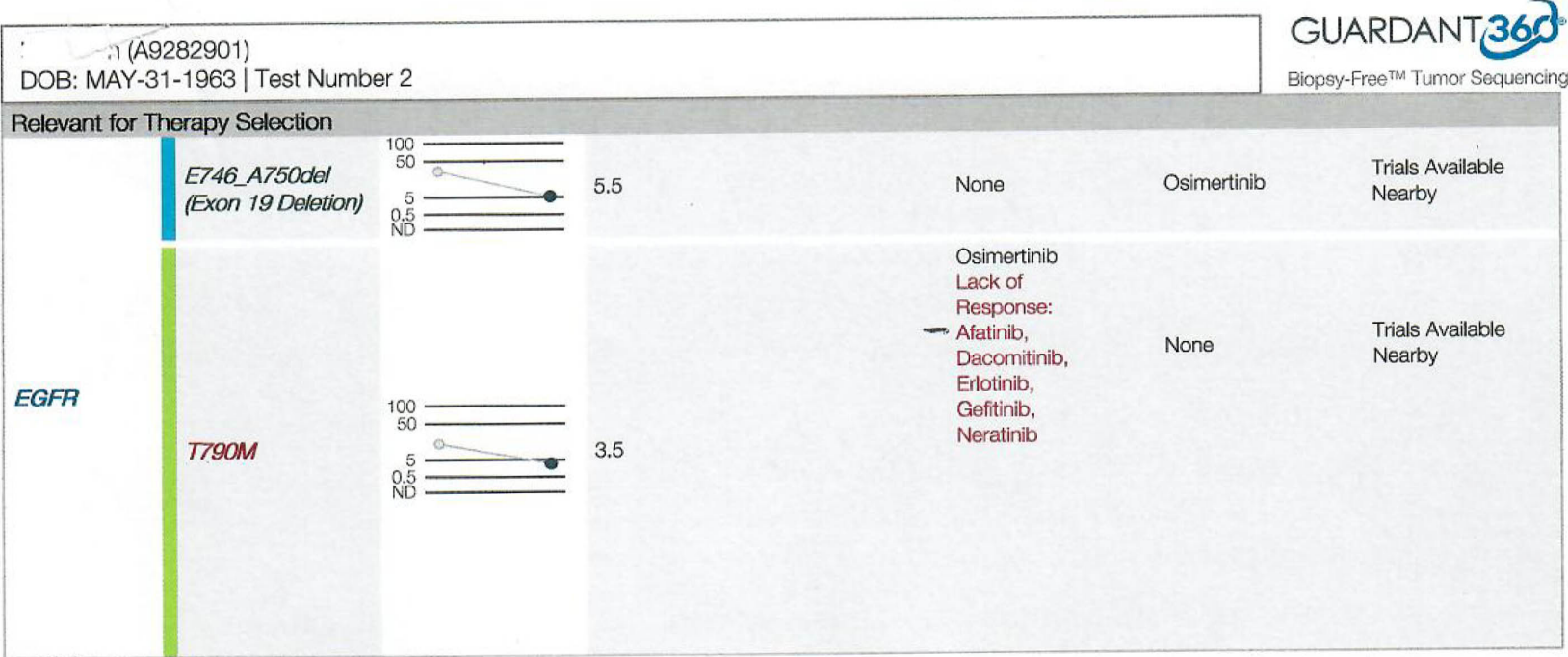

\begin{tabular}{|c|c|c|c|c|c|c|}
\hline$A P C$ & L548fs & 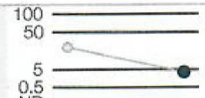 & 3.9 & None & Celecoxib & Trials Available \\
\hline KIT & $A M P$ & $\mathrm{ND}^{+++}=$ & + & None & $\begin{array}{l}\text { Axitinib, } \\
\text { Cabozantinib, } \\
\text { Dasatinib, } \\
\text { Imatinib, } \\
\text { Lenvatinib, } \\
\text { More drugs } \\
\text { available }\end{array}$ & $\begin{array}{l}\text { Trials Available } \\
\text { Nearby }\end{array}$ \\
\hline
\end{tabular}

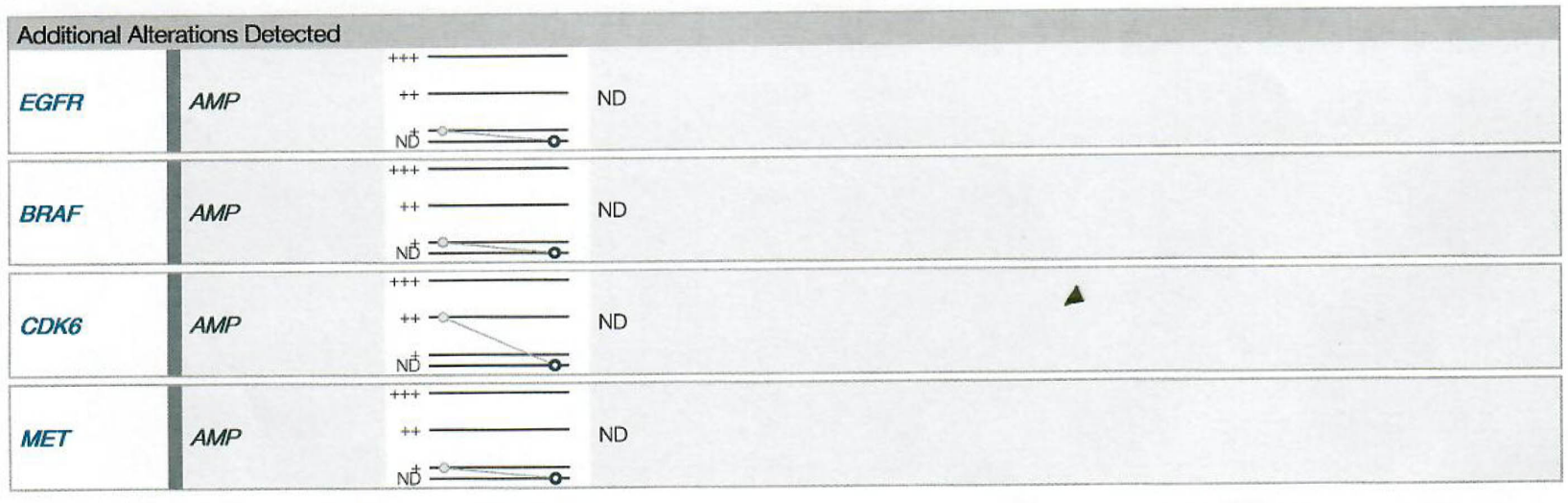

The chart above annotates the allele frequency of altered circulating cell-free DNA (\% cfDNA) detected in this patient. Alterations are listed in descending order of \% cfDNA by gene.

All therapeutic annotations are based on publicly available information as described in the "Detailed Therapy Results" and "Clinical Relevance of Detected Alterations" sections of the report.

Genomic Alterations: Not Detected (ND). Genomic alterations may be present that are below the limit of detection of this test. Certain sample or variant characteristics may result in reduced analytic sensitivity, such as poor sample quality or improper collection. Genomic alterations in a tumor may be present, but are not detected in circulating cellfree DNA from this blood specimen with this test.

GUARDANTHEALTH ${ }^{\circ}$ For a more detailed Guardant360 Patient Report, log onto: https://portal.guardanthealth.com or to set up an account, contact Client Services: 855.698 .8887

Figure 1. Circulating DNA, pre and post MTET therapy. 


$$
\text { (A8186101) }
$$

DOB: OCT-23-1962 | Test Number 1

Patient

MRN

GENDER

Male

CLINICAL DIAGNOSIS

Lung adenocarcinoma

\section{Reporting}

REPORT DATE

DEC-19-2017

RECEIPT DATE DEC-12-2017

COUFCTION DATE

DEC-11-2017

SPECIMEN

Blood
Physician

NAME

Mohammad Amin Nezami

ACCOUNT

Orange Coast Medical Center of Hope

496 Old Newport Blvd Ste 7, Newport Beach, CA 92663

PHONE

(949) 515-4673

FAX

(949) $515-4672$

ADDITIONAL RECIPIENT

Guardant360 Tumor Response Map

The Guardant360 Tumor Response Map illustrates the mutant allele percentage (\% cfDNA) of observed somatic variants at each sample submission time point. The "Somatic Alteration Burden" value below refers to the maximum \% cfDNA detected at each time point. Amplifications are not plotted, and only the first and last four test dates are plotted. Please see the Physician Portal (https://portal.guardanthealth.com) for the Tumor Response Map with all test dates.

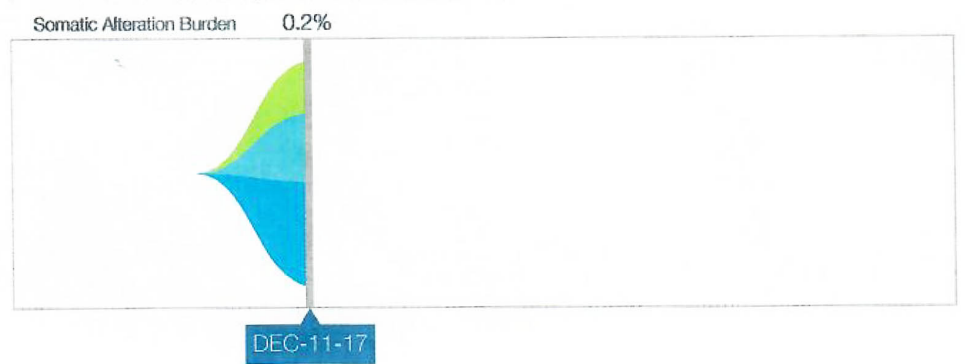

3 Total Somatic Alteration(s) Detected

1 with Associated Therapy

0 Associated with Lack of Response

Multiple Clinical Trials Available

Summary of Somatic Alterations \& Associated Treatment Options

The percentage of altered cell-free DNA $\%$ cfDNA) circulating in blood is related to the unique tumor biology of each patient. Factors that may affect the \% cfDNA of detected somatic alterations include tumor growth, tum-over, size, heterogeneity, vascularization, disease progression, and treatment.

\begin{tabular}{|c|c|c|c|c|c|}
\hline Alteration & & $\begin{array}{l}\% \text { cfDNA or } \\
\text { Amplification }\end{array}$ & $\begin{array}{l}\text { FDA Approved in } \\
\text { Indication } \\
\text { ses page } 3\end{array}$ & $\begin{array}{l}\text { Available for Use in Other } \\
\text { Indications } \\
\text { soo page } 3\end{array}$ & $\begin{array}{l}\text { Clinical Drug Trials } \\
\text { see page } 7\end{array}$ \\
\hline \multicolumn{6}{|c|}{ Relevant for Therapy Selection } \\
\hline EGFR & $\begin{array}{l}\text { E746_A750del } \\
\text { (Exon } 19 \text { Deletion) }\end{array}$ & 0.1 & $\begin{array}{l}\text { Afatinib, } \\
\text { Erlotinib, } \\
\text { Geftitinib }\end{array}$ & $\begin{array}{l}\text { Neratinib, } \\
\text { Osimertinib }\end{array}$ & Trials Available Nearby \\
\hline TP53 & R158_A159del & 0.1 & None & None & Trials Avalable \\
\hline \multicolumn{6}{|c|}{ Additional Alterations Detected } \\
\hline$R B 1$ & $Y 771^{*}$ & 0.2 & None & None & None \\
\hline
\end{tabular}

The chart above annotates the allele frequency of altered circulating cell-free DNA (\% cfDNA) detected in this patient. Alterations are listed in descending order of \% cfDNA by gene.

All therapeutic annotations are based on publicly available information as described in the "Detailed Therapy Results" and "Clinical Relevance of Detected Alterations" sections of the report.

GUARDANTHEALTH' For a more detailed Guardant360 Patient Report, log onto: https://portal.guardanthealth.com or to set up an account, contact Client Services: 855.698 .8887

Figure 2. Circulating DNA Pre treatment. 
Immediately he was started on IV epigenetic therapies which he received on dailybasis, starting in December $5^{\text {th }}$, 2017. Immediately he was feeling better, and able to walk after two weeks of therapy.

His post treatment labs after ten days showed CEA decreased from 14.4, measured on 12/8/17 down to 10.6 measured on 12/21/17. Further his TGF and CEA dropped again after two weeks of therapies. His TGF dropped down to 9235 from 12201, and CEA decreased to 5.1 on 1/11/8. Further tested on 1/18/18 and it came down to 3.7 (normalized). Clinically he improved, with ability to stop the steroids all together.

His c DNA showed a drastic response after two weeks of treatments, with RB1 and TP53 both non detectable. (Please see Figure 3).

This was repeated on 3/16/18 and still was nondetectable. At this time patient was receiving once a week therapy. His oncologist ha called his progress "exceptional". His radiological response has confirmed his skeletal lesions essentially resolved on 2/20/18 scan and his brain lesions have also dropped from $2.3 \mathrm{~cm}$ largest mass to $9 \times 6 \mathrm{~mm}$ in size verified in his MRI of 2/20/18.

Further his TGF dropped down to 8884 from 12202 in 8 weeks. (measured on 2/2/18 and 12/2/17). His Brain MRI showed 70 percent reduction in all brain lesions volumetric size in February 2018. On 4/9/18 his MRI showed that there was reduction of brain mets in right parietal lobe from 9 to $6 \mathrm{~mm}$, and this time no enhancement seen, Left parietal focus down to $2 \mathrm{~mm}$ from 4 . Previous left posterior frontal, right inferior frontal, right cerebellar, foci no longer seen.

His PET scan on 2/20/18 showed complete resolution of wide metastatic disease in the skeletal bone as well as pleura, abdomen, pelvis, right hilar, LN. Her pulmonary mass also appeared smaller with less peribronchovascular changes. The size decreased from $2.9 \mathrm{~cm}$ to $0.9 \mathrm{~cm}$ and the SUV activity dropped from 9.1 to 1.3 .

Then between months of 6/13/18 and 8/19/18 he was unable to receive epigenetic treatments and continued afatinib alone. As a result patient developed new lesion in his brain MRI along with increased circulating DNA (evident in his liquid biopsy) dated August $9^{\text {th }}, 2018$. (Please see Figure 4).

\section{Results}

In case number 1, a mutated EGFR tumor responds to epigenetic therapy in combination with afatinib (where afatanib by itself had failed).

In case number 2, anon mutated EGFR responds to Afatinib in combination with epigenetic therapy in an expedited fashion, and discontinuation of epigenetic therapy, causes development of resistance to Afatinib through mutation of T790M.

Since the only variable during this time was discontinuation of Epigenetic therapies, and the relapses were secondary to development of EGFR T790M mutation, we conclude that epigenetic therapies had caused durable response in combination with EGFR inhibition both in non mutated and mutated EGFR target at T790M. 


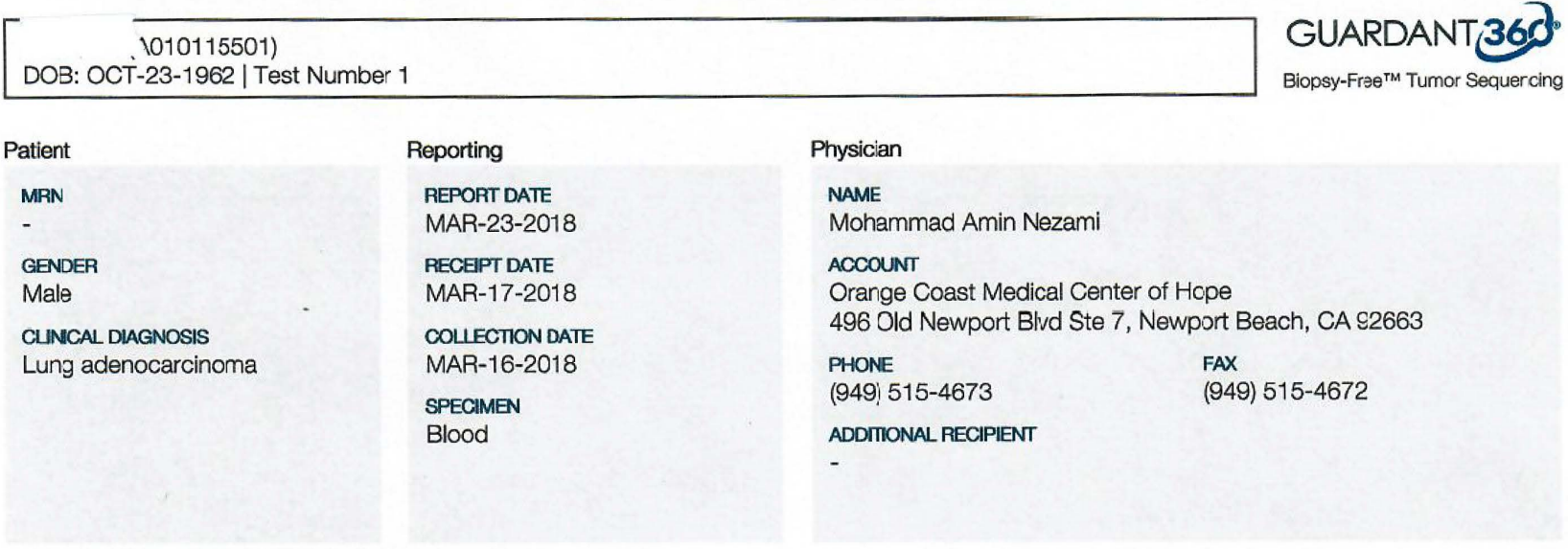

\section{Guardant360 Tumor Response Map}

The Guardant360 Tumor Response Map illustrates the mutant allele percentage (\% cfDNA) of observed somatic variants at each sample submission time point. The "Somatic Alteration Burden" value jelow refers to the maximum \% cfDNA detected at each time point. Amplifications are not plotted, and only the first and last four test dates are plottec. Please see the Physician Portal (https://portal.guardanthealth.com) for the Tumor Response Map with all test dates.

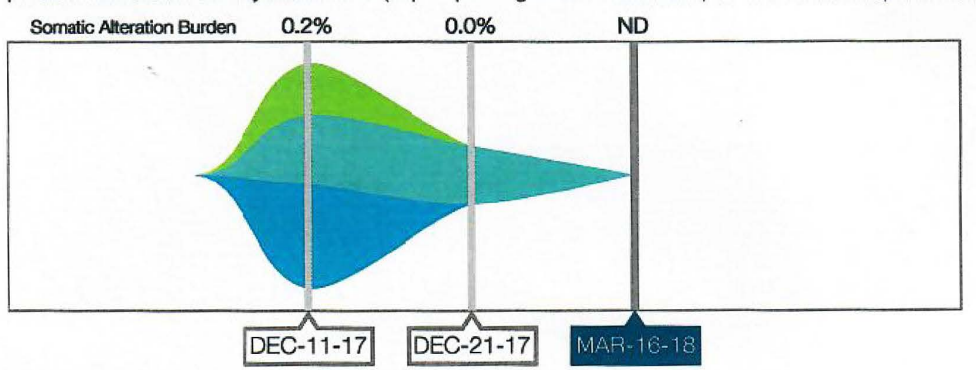

\section{Total Somatic Alteration(s) Detected}

Somatic Alterations: Not Detected (ND). Sonatic alterations may be present tha: are below the limt of detection of this test. Certain sample or variant characteristics may result in reduced analytic sensitivity. The absence of detectable somatic alterations in circulating cell-free DNA does not preclude the presence of somatic alterations in the tumor.

Summary of Somatic Alterations \& Associated Treatment Options

The percentage of altered cell-free DNA (\% cfDNA) circulating in blood is related to the unique tumor biology of each patient. Factors that may affect the \% cfDNA of detected somatic alterations include tumor growth, turn-over, size, heterogeneity, vascularization, disease progression, and treatment.

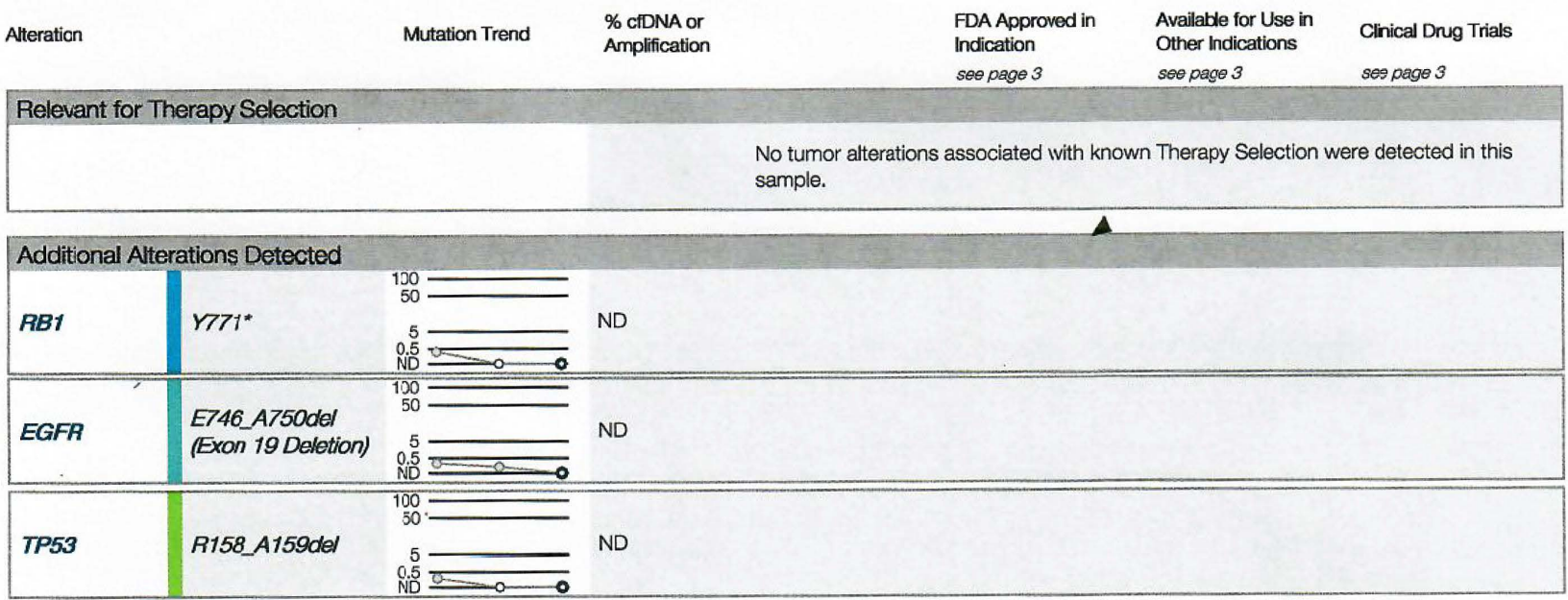

GUARDANTHEALTH ${ }^{\circ}$ For a more detailed Guardant360 Patient Report, log onto: https://portal.guardanthealth.com or to set up an account, contact Client Services: 855.698 .8887

Figure 3. c DNA post MTET therapy. 


\section{Guardant360 Tumor Response Map}

The Guardant360 Tumor Response Map llustrates the mutant allele percentage (\% cfDNA) of observed somatic variants at each sample submission time point. Amplifications are not plotted, and only the first and last flve test dates are plotted. Please see the Physician Portal (portal.guardanthealth.com) for the Tumor Fesponse Map with all test dates.

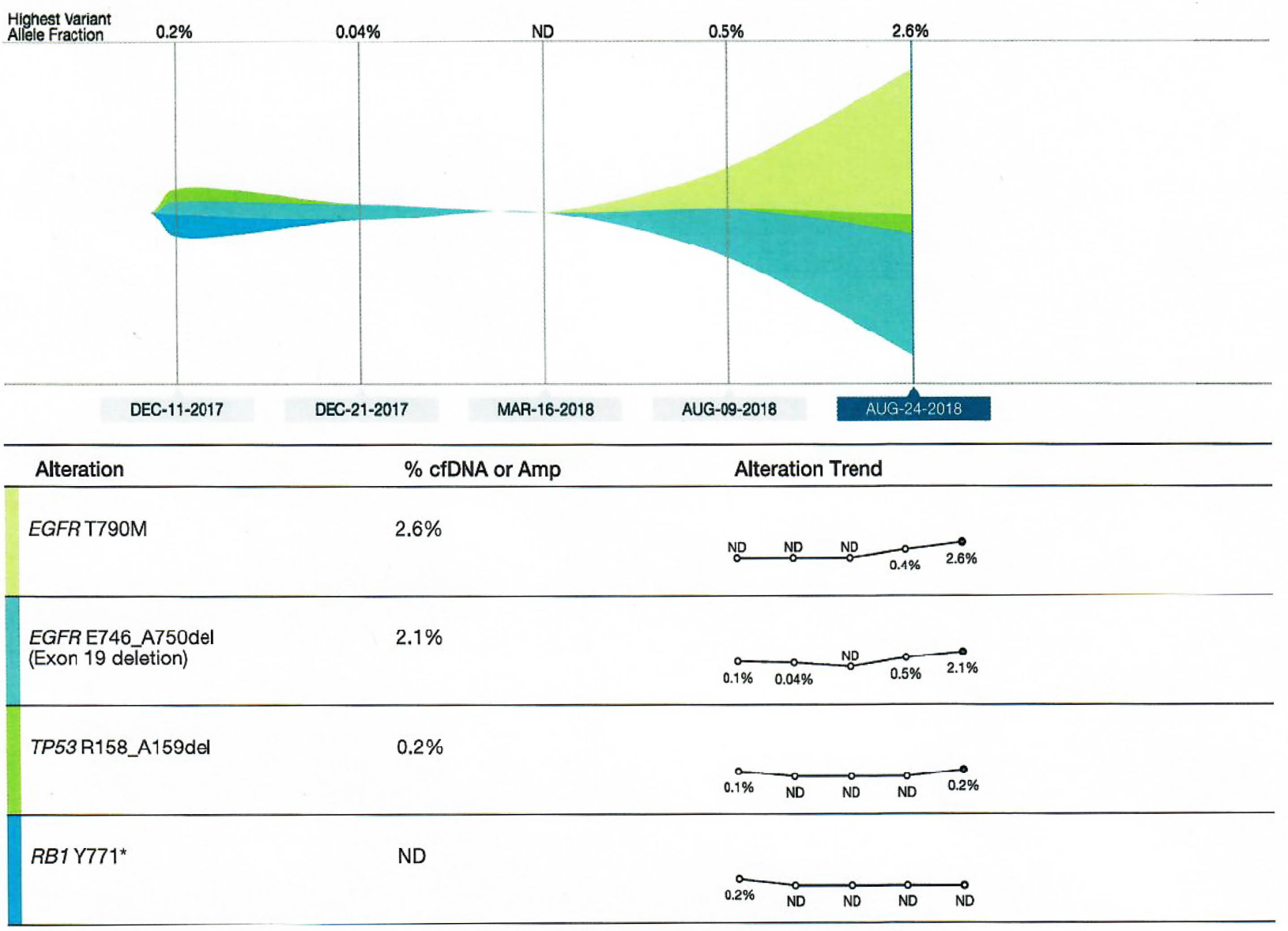

The table above annotates the variant allele fraction (\% cfDNA) detected in this sample, listed in descencing order.

Figure 4. Circulating DNA after withdrawal of MTET therapy. 


\section{Conclusion}

Treatment of EGFR mutated adenocarcinoma is complex and prolonged survival is challenging. This study although represents small number of cases, the effect size is major in both cases, apparent on major molecular response reported. We recommend a controlled trial with combination of MTET and EGFR targeted therapy to prove such concept with hypothesis of accomplished durable response as primary aim. We propose to implement the standard use of liquid genomic biopsies in the EGFR positive subset of non small lung cancer patients as a means of monitoring response, as early as days after initiation of epigenetic therapy. We believe such results could impact the standard of care in treating lung cancer and providing a meaningful improved survival to the patients with advanced disease.

\section{Conflicts of Interest}

The authors declare no conflicts of interest regarding the publication of this paper.

\section{References}

[1] Zhao, M., Zhang, Y., Li, J., Li, X., Cheng, N., Wang, Q., Cai, W., Zhao, C., He, Y., Chang, J. and Zhou, C. (2018) Histone Deacetylation, as Opposed to Promoter Methylation, Results in Epigenetic BIM Silencing and Resistance to EGFR TKI in NSCLC. Oncology Letters, 15, 1089-1096.

[2] Kwapisz, D. (2017) The First Liquid Biopsy Test Approved. Is It A New Era of Mutation Testing for Non-Small Cell Lung Cancer? Annals of Translational Medicine, 5, 46. https://doi.org/10.21037/atm.2017.01.32

[3] Sakr, L., Kasymjanova, G., Small, D.I., Cohen, V., Galvis, L. and Pepe, C. (2017) Predicting Duration of Response to EGFR TKI among EGFR-Mutant NSCLC Patients. Journal of Clinical Oncology, 34.

[4] Sullivan, I. and Planchard, D. (2017) Next-Generation EGFR Tyrosine Kinase Inhibitors for Treating EGFR-Mutant. Frontiers in Medicine (Lausanne), 3, 76.

[5] Arcila, M.E., Oxnard, G.R., Nafa, K., Riely, G.J., Solomon, S.B., Zakowski, M.F., Kris, M.G., Pao, W., Miller, V.A. and Ladanyi, M. (2011) Rebiopsy of Lung Cancer Patients with Acquired Resistance to EGFR Inhibitors and Enhanced Detection of the T790M Mutation Using a Locked Nucleic Acid-Based Assay. Clinical Cancer Research, 17, 1169-1180. https://doi.org/10.1158/1078-0432.CCR-10-2277

[6] Yano, S., Yamada, T., Takeuchi, S., Tachibana, K., Minami, Y., Yatabe, Y., Mitsudomi, T., Tanaka, H., Kimura, T., Kudoh, S., Nokihara, H., Ohe, Y., Yokota, J., Uramoto, H., Yasumoto, K., Kiura, K., Higashiyama, M., Oda, M., Saito, H., Yoshida, J., Kondoh, K. and Noguchi, M. (2011) Hepatocyte Growth Factor Expression in EGFR Mutant Lung Cancer with Intrinsic and Acquired Resistance to Tyrosine Kinase Inhibitors in a Japanese Cohort. Journal of Thoracic Oncology, 6, 2011-2017. https://doi.org/10.1097/JTO.0b013e31823ab0dd

[7] Britten, C.D., Adjei, A.A., Millham, R., Houk, B.E., Borzillo, G., Pierce, K., Wainberg, Z.A. and Lorusso, P.M. (2014) Phase I Study of PF-04691502, a Small-Molecule, Oral, Dual Inhibitor of PI3K and mTOR, in Patients with Advanced Cancer. Investigational New Drugs, 32, 510-517. https://doi.org/10.1007/s10637-013-0062-5 
[8] Yauch, R.L., Januario, T., Eberhard, D.A., Cavet, G., Zhu, W., Fu, L., Pham, T.Q., Soriano, R., Stinson, J., Seshagiri, S., Modrusan, Z., Lin, C.Y., O’Neill, V. and Amler, L.C. (2005) Epithelial versus Mesenchymal Phenotype Determines In Vitro Sensitivity and Predicts Clinical Activity of Erlotinib in Lung Cancer Patients. Clinical Cancer Research, 11, 8686-8698. https://doi.org/10.1158/1078-0432.CCR-05-1492

[9] Thomson, S., Buck, E., Petti, F., Griffin, G., Brown, E., Ramnarine, N., Iwata, K.K., Gibson, N. and Haley, J.D. (2005) Epithelial to Mesenchymal Transition Is a Determinant of Sensitivity of Non-Small-Cell Lung Carcinoma Cell Lines and Xenografts to Epidermal Growth Factor Receptor Inhibition. Cancer Research, 65, 9455-9462. https://doi.org/10.1158/0008-5472.CAN-05-1058

[10] Lin, Y.X., Wang, X. and Jin, H.C. (2014) EGFR-TKI Resistance in NSCLC Patients: Mechanisms and Strategies. American Journal of Cancer Research, 4, 411-435. 